\title{
$\mathrm{PH} 101_{\text {cosate }}$
}

a debate Hacia una nueva institucionalidad cultural. Modelos emergentes de gestión...

| coordina Jesús Carrillo Castillo

\section{Decrecimiento cultural: tentativas desde los ecofeminismos}

\author{
Javier Rodrigo Montero | Transductores \\ URL de la contribución <www.iaph.es/revistaph/index.php/revistaph/article/view/4716>
}

En este pequeño texto queremos revisar y repensar algunas tentativas sobre las políticas culturales si las resituamos a partir de la madeja de los feminismos, pensando en un cambio a dos escalas y arcos: una de tamaño micro y de transición inminente y otra de tamaño macro-profundo y de arco temporal expandido. Si la pregunta clave del eco-feminismo es cómo trabajamos el conflicto del capital-vida, la reflexión sobre la cultura debe responder a los mismos retos: a cómo desbordar este binomio, a cómo dejar que la vida tenga presencia. Este reto supone una doble afectación en la cultura: demarcaría sus políticas por la perspectiva ecosocial, poner la vida en el centro; y, al mismo tiempo, supondría repensar cómo la cultura también puede aportar sus elementos específicos y saberes, con su capacidades de imaginación política, de dotarnos de otras formas de pensarnos, narrarnos, de habitar y sostener la vida en común.

Este doble vínculo, este nudo doble interconectado, comporta diversas consecuencias para el trabajo sobre políticas culturales. De forma somera relataremos algunas de ellas.

\section{Formas multidimensionales}

En primer lugar, cabe pensar las formas multidimensionales de desarrollar un tránsito ecosocial. Como muchos movimientos ecologistas y sociales, entendemos que estas propuestas son vectores de cambio; es decir, son espacios en proceso, en cuestión. Requieren un tránsito hacia un nuevo ecosistema donde la mirada eco-social sobre la cultura desborde su campo de acción. Supone activar una mirada más amplia de la cultura, como bien común y, por tanto, como un conjunto de ecosistemas vivos y orgánicos: como políticas culturales, como conjunto de prácticas y ecosistemas con condiciones eco-sociales concretas, donde la cultura no se debate solo por los agentes expertos o profesionales del sec- tor, sino que se amplía y trabaja en común entre diversos saberes, actores y agentes, tanto ciudadanos como otros que también tejen ecosistemas culturales (sobre esto volveremos más adelante). Si la cultura es un bien común, es interesante repasar, reactivar y repensar las formas comunales de gestionar recursos comunes y de cuidarlos (agua, pesca, bosques, cuidados, medicina y salud comunitarias). Revisar estas formas para aprender e implementar otros indicadores sobre el modelo de políticas culturales es un reto. Estas formas pueden dotarnos de otros modelos donde reactivar la cultura como derecho social y comunal, como un espacio donde lo reproductivo tenga más peso que la denostada capa productivista y desarrollista. Superar la mirada de la cultura como recurso económico neoliberal, como producto para ciertas élites, como cultura transgénica que arrasa el terreno y cultivos de base bajo marcas globales y macro-eventos (actúa como la industria de la soja). La cultura que se basa en el PIB y el impacto de las industrias culturales en parámetros de turismo y productividad mayoritariamente, para justificar que hay que salvar la cultura y que la cultura constituye además un espacio celebratorio donde volver a la normalidad.

\section{Enredar-nos desde la cultura}

Y esta reflexión nos hace de puente para el segundo eje de trabajo: la capacidad de enredar-nos desde la cultura en alianza con otras luchas ecosociales y de justicia social. Implica desbordar el marco de lo que denominamos cultura desde una hegemonía política clara. Desbordar qué es la cultura y cómo se debe gestionar correctamente; y su figura construida bajo el mito del sujeto moderno independiente: la hegemonía del gestor cultural neoliberal. Esta segunda consecuencia nos abre un reto clave: deselitizar y despatriarquizar la cultura, quitarle su marco de sujetos blancos, burgueses, varones y autónomos (el famoso BBVA). Repensarla como un trabajo cultural inter-dependiente y eco-depen- 

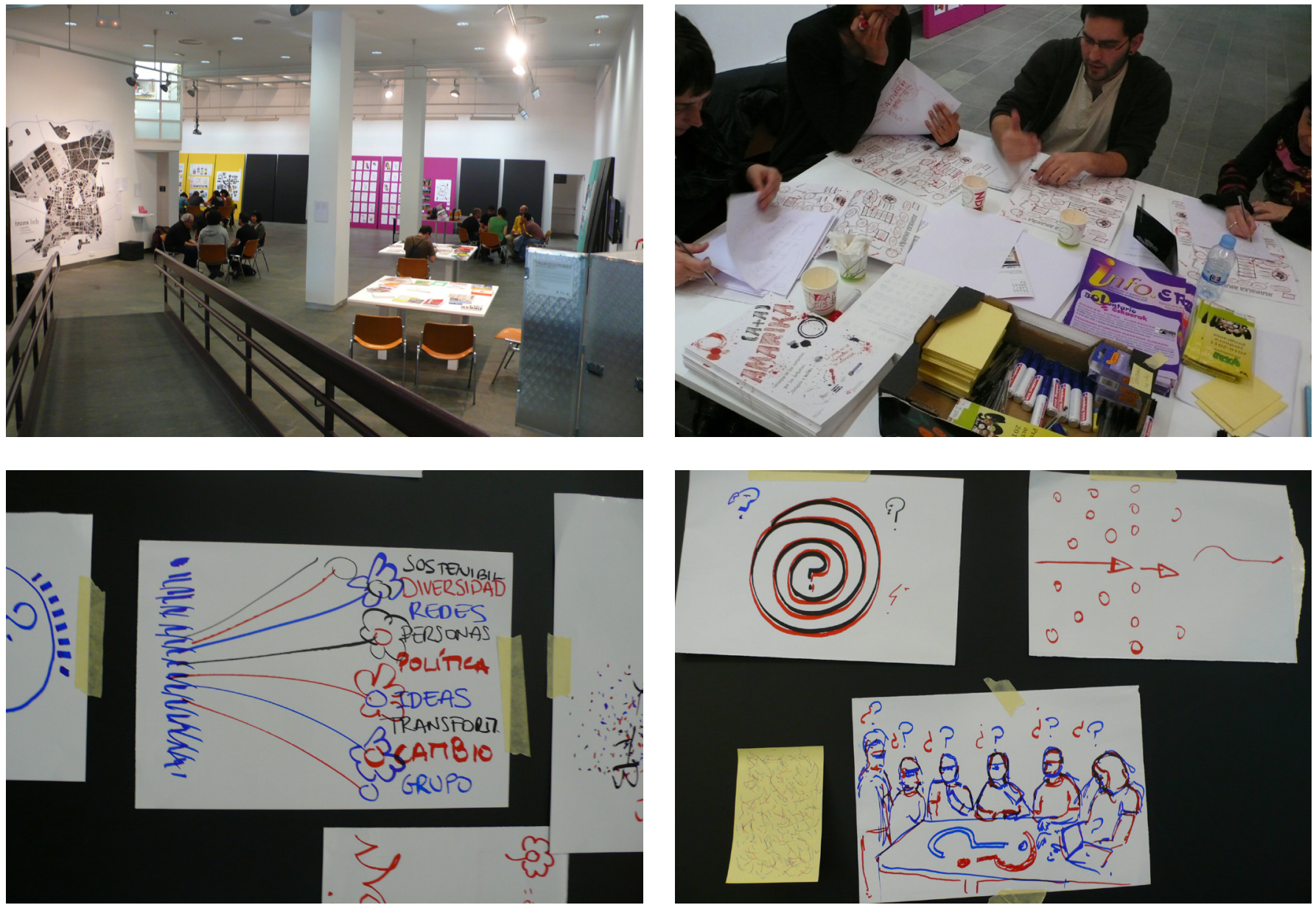

Translab amarika. Laboratorio ciudadano de pedagogías en red. Sala Amarika, abril 2011 | fotos Transductores

diente de otros campos, saberes y luchas sociales: del derecho a la ciudad, de la vivienda digna, de las cuidadoras y trabajadoras domésticas, de las redes de soporte mutuo, de la educación viva y feminista, etc. Es decir, entender la capacidad de generar marcos comunes y alianzas anómalas y plurales de las trabajadoras culturales, de sus prácticas en relación a los temas, condiciones materiales y movimientos emergentes de los diversos tejidos comunitarios, luchas sociales y marcos ecosociales.

\section{Decrecimiento cultural}

La tercera implicación que hay que resaltar sería cómo ir más allá de un newgreen deal en cultura un decreci- miento cultural. De algún modo, desarrollar movimientos y vectores hacia el decrecimiento es urgente más que nunca, y la delgada línea roja del post-desarrollismo y la normalidad anterior como estado positivo es uno de los riesgos mas complejos de dirimir. Hemos visto muchas muestras de programas y procesos culturales en los que se ha pedido salvar la cultura y generar nuevos espacios de celebración y festividad, que recuerdan más a los formatos de macro-eventos pasados en consonancia con las medidas de seguridad, el discurso de las ciudades marca y el turismo cultural interior o local que, sin embargo, no dan pie a que se puedan repensar otras formas de producción cultural o de gobernanza compartida (de quién y cómo se decide sobre estos programas) 
a debate Hacia una nueva institucionalidad cultural. Modelos emergentes de gestión...

| coordina Jesús Carrillo Castillo

y otros modos de cuidar y generar prácticas culturales inter y ecodependientes.

\section{Nuevo marco público-comunitario}

La cuarta implicación tendría que ver con comenzar a experimentar un nuevo marco público-comunitario que supere el denostado marco público-privado que tanto ha marcado las políticas culturales (como consecuencia de la externalización de servicios y las sucesivas neoliberizaciones de las políticas públicas desde los 90 y agudizados en 2008 y seguramente en esta nueva crisis). Esta perspectiva ayudaría a pensar cómo se pueden trenzar alianzas desde los tejidos y economías comunitarias con las políticas públicas para trazar otras nuevas formas de repensar las instituciones culturales, las políticas publicas en cultura y sus diversos impactos comunitarios. Estos marcos pueden ser trabajados en instituciones nuevas o experimentales que recojan la tradición de la gestión comunitaria o la gestión vecinal, o también en micro-escalas con procesos y programas de escala social y micro en instituciones: por ejemplo un programa experimental eco-social de mediación, un trabajo de cocina-huerto comunitario en un centro de arte, un bar gestionado por cooperativas de auto-empleo, en un teatro nacional, etc.

\section{Sentido común y público}

La quinta implicación, la más macro y costosa, tiene que ver lógicamente con cambiar los criterios públicos de marcos administrativos a largo plazo. Es decir, cambiar la normativa -no como excepción sino como un sentido común y público- sobre gestión cultural. Consistiría en aplicar otros criterios, indicadores y elementos a las políticas culturales que estuvieran impregnados de los valores de la economía social y solidaria, de los feminismos, pensando en micro mercados sociales y ecosistemas cooperativistas donde las instituciones culturales pueden tejer sus mimbres conjuntamente con tejidos productivo locales y solidarios. Supondría un cambio de normativa virtuoso y factible, si somos capaces de armarnos de los saberes laborales y legales, y de transferir experimentos recientes a macroescalas. En este sentido es urgente generar otras forma de licitación y pública con- currencia, con indicadores comunitarios, con pliegos de concursos diseñados con indicadores cualitativos mayoritariamente y cláusulas sociales codiseñadas entre administración y comunidad. Y el gran reto es hacerlo con las figuras técnicas de la administración pública para ir generando normativa público-comunitaria. Este tránsito supone cambiar el hardware de la administración pública para que sea compatible con un software libre y abierto. Estas formas podrían afectar a múltiples capas de la gestión cultural: desde el concurso de educación/ mediación, a comunicación, servicios técnicos, montaje de exposiciones, producción de fiestas de barrios o de otros eventos, etc. De este modo, se podría limitar y gestionar el acceso de las grandes empresas y monopolios a los pliegos de concursos públicos donde se mueven muchas partidas de dinero público. Se trataría de favorecer tejidos de micro-empresas y mercados sociales en torno a las instituciones culturales de la administración pública y otros programas para generar retornos directos y ecosistemas sostenibles y saludables para todas. 